\title{
STUDI DESKRIPTIF-KOMPARATIF SIMTOM KECEMASAN DAN DEPRESI PADA MAHASISWA/I DI UNIVERSITAS X
}

\author{
Vivian Chandra ${ }^{1}$, Monty P. Satiadarma ${ }^{2}$, Widya Risnawaty ${ }^{3}$ \\ ${ }^{1}$ Prodi Magister Psikologi Profesi, Universitas Tarumanagara Jakarta \\ Email: vivian.717172013@stu.untar.ac.id \\ ${ }^{2}$ Program Studi Psikologi, Universitas Tarumangara Jakarta \\ Email: montys@fpsi.untar.ac.id, \\ ${ }^{3}$ Program Studi Psikologi, Universitas Tarumangara Jakarta \\ Email:widyar@fpsi.untar.ac.id
}

Masuk : 16-03-2020, revisi: 28-04-2020, diterima untuk diterbitkan : 30-04-2020

\begin{abstract}
College students are facing transitions in many aspects, and one of them is the educational challenges. Various types of academic stress may cause anxiety and depression. Hence, it is necessary to provide a description of anxiety and depression prevalences for further interventions. Researchers used DASS as screening instrument and gathered data from 371 students. From these findings, there were more students with anxiety or depression symptoms than those who did not. Anxiety was most found in moderate degree; while depression was most found in mild degree. Such results indicated that mental health awareness and psychological services are necessary to be endorsed for the sake of students' wellbeing.
\end{abstract}

Keywords: depression, anxiety, college students

\begin{abstract}
ABSTRAK
Mahasiswa merupakan kelompok populasi yang mengalami transisi dalam berbagai aspek, salah satunya adalah dalam tantangan pendidikan. Ragam tantangan dalam dunia perkuliahan berpotensi untuk menyebabkan permasalahan psikologis, seperti stress dan depresi. Oleh karena itu, perlu diperoleh gambaran mengenai simtom kecemasan dan depresi guna ditindaklanjuti. Peneliti menggunakan kuesioner DASS sebagai instrument skrining pada 371 mahasiswa. Dari hasil temuan, ternyata lebih banyak mahasiswa/i yang mengalami simtom kecemasan atau depresi dibandingkan yang tidak mengalami simtom. Tingkat kecemasan yang paling prevalen adalah taraf sedang; taraf depresi yang paling prevalen adalah taraf ringan. Berdasarkan pemaparan data, kesadaran akan kesehatan mental dan layanan psikologis perlu untuk digalakkan demi kesejahteraan mental mahasiswa.
\end{abstract}

Kata Kunci: kecemasan, depresi, mahasiswa

\section{PENDAHULUAN \\ Latar Belakang}

Setelah seseorang lulus dari sekolah, maka ia memiliki kesempatan untuk menekuni minat studi dengan mengikuti perkuliahan. Universitas menjadi lembaga bagi mahasiswa untuk mendalami jurusan yang diminati. Meskipun memberikan layanan pendidikan, universitas memiliki beberapa perbedaan dari sekolah dari segi cara belajar. Mahasiswa belajar di lingkungan yang lebih independen daripada ketika masih di SMA, memiliki jadwal yang lebih fleksibel, mengatur waktu sendiri (time management), dan belajar bertanggung jawab atas keputusan sendiri (Mutch, 2005). Hal ini menyebabkan mahasiswa perlu menyesuaikan diri dengan lingkungan belajar yang baru. Selain itu, terdapat pula tantangan yang baru dalam dunia perkuliahan, yakni standar nilai, ujian, materi dan manajemen waktu (Crocker \& Luhtanen, 2003; Kumaraswamy, 2013; Misra \& McKean, 2000). Di samping masalah akademik, mahasiswa perlu mewaspadai masalah non akademik yang mungkin dihadapi. Beberapa masalah non-akademik seperti imej tubuh yang buruk, kepuasan hidup yang rendah, rasa rendah diri, ketidakstabilan kondisi finansial, pola tidur, tuntutan orangtua, konflik pertemanan, dan konflik pasangan juga dapat timbul di masa perkuliahan (Kostanski \& Gullone, 1998; Lifespan News, 2006; Goswami et al., 2006; Eisenberg et al., 2007; Orzech, et al., 2011; Kai-Wen, 2009). 
Berbagai jenis permasalahan saat menjalani masa perkuliahan dapat menyebabkan seseorang untuk mengalami kecemasan dan depresi. Saat mahasiswa mengalami kecemasan atau depresi, maka akan berdampak ke aspek kehidupan lainnya. Beberapa studi menjelaskan bahwa kecemasan dan depresi dapat mengakibatkan performa akademik yang menurun, pola hidup yang berisiko, dan kualitas hidup yang menurun (Mihailescu, Diaconescu, Ciobano, Donisan, dan Mihailescu, 2016; Doom \& Haeffel, 2013; Barrera \& Norton, 2009).

Melihat dampak dari kecemasan dan depresi pada aspek akademik maupun non akademik, maka diperlukan gambaran mengenai kecemasan dan depresi pada mahasiswa. Dengan adanya deskripsi data, maka kemungkinan tindak lanjut dapat dilakukan. Hal ini dapat menjadi pertimbangan bagi, baik dari segi kebijakan universitas maupun intervensi, seperti dalam studi deskriptif simtom depresi maupun kecemasan yang sudah pernah dilakukan sebelumnya (Trisnaramawati, Satiadarma, \& Soetikno, 2019; Tania, Soetikno, \& Suparman, 2019). Studi tersebut membantu dalam memberikan gambaran kecemasan dan depresi yang dialami oleh populasi penderita penyakit sehingga dapat disarankan untuk menindaklanjuti, secara medis maupun psikologis.

Rumusan masalah pada penelitian ini adalah "Bagaimana gambaran simtom kecemasan dan depresi pada mahasiswa/i di universitas X?"

\section{METODE PENELITIAN}

\section{Partisipan dan Prosedur Penelitian}

Penelitian menggunakan metode deskriptif, yakni pendekatan penelitian yang bertujuan mengumpulkan dan/atau menganalisis data untuk menggambarkan karakteristik kelompok, konsep, atau fenomena. Penelitian deskriptif dapat bersifat kuantitatif maupun kualitatif. Metode deskriptif kuantitatif umumnya menggunakan survei, alat ukur, grafis, alat ukur fisiologis, metaa-analisis, dan analisis data sekunder. Sedangkan metode deskriptif kualitatif menggunakan wawancara, focused group discussion, analisis konten, observasi, tinjauan literatur, studi kasus, studi etnografi, maupun studi fenomenologi (Tarzian \& Cohen, 2012). Penelitian ini menggunakan pendekatan deskriptif kuantitatif dengan teknik pengumpulan data berupa kuesioner (survei). Partisipan dalam penelitian adalah mahasiswa yang sedang menjalankan pendidikan di Universitas X. Metode sampling yang digunakan adalah incidental sampling, sebuah metode yang menggunakan partisipan yang paling mudah diakses dan bersedia berpartisipasi (Schneider, Whitehead, LoBiondo-Wood, \& Haber, 2013).

\section{Instrumen Penelitian}

Adapun instrumen yang digunakan dalam penelitian adalah Depression Anxiety Stress Scale (DASS) yang diciptakan oleh Lovibond dan Lovibond (1995). Alat ukur tersebut terdiri dari 42 butir dan mengukur tiga skala, yakni simtom kecemasan, depresi, dan stress. Masing-masing skala memiliki jumlah butir sebanyak 14 pernyataan. DASS diisi menggunakan skala Likert dengan rentang 0-3. Skala 'depresi' melihat karakteristik berupa sifat meremehkan diri, putus asa, murung, keyakinan bahwa hidup tidak memiliki makna atau tujuan, pesimisme terkait masa depan, anhedonia, ketidakmampuan untuk melibatkan diri dalam sesuatu, mengalami retardasi psikomotorik, dan berkurangnya inisiatif. Skala 'kecemasan' melihat karakteristik berupa rasa gelisah, gugup, gemetaran, kondisi mulut yang kering, kesulitan bernafas, detakan jantung yang cepat, kondisi telapak tangan yang rentan berkeringat, kekhawatiran akan performa, dan takut kehilangan kendali. Skala 'stress' mengukur kesulitan untuk rileks, rangsang sistem saraf, mudah gelisah, overreaktif, dan sikap tidak sabar. Berdasarkan kategori yang telah ditentukan, skor tiap skala akan dikategorikan dalam rentang normal, ringan (mild), sedang (moderate), parah (severe) 
hingga sangat parah (extremely severe) (Lovibond \& Lovibond, 1995). Dalam penelitian ini, peneliti berfokus pada skala depresi dan kecemasan saja. Peneliti menggunakan instrumen DASS yang sudah diterjemahkan ke dalam bahasa Indonesia oleh Damanik (2006). Alat ukur memiliki konsistensi internal yang baik ( $\alpha=.90$ untuk subskala depresi, $\alpha=.88$ untuk subskala stress, dan $\alpha=.85$ untuk subskala kecemasan).

\section{HASIL DAN PEMBAHASAN}

Dari penyebaran kuesioner DASS, peneliti berhasil mengumpulkan 371 mahasiswa dengan rincian: (a) 180 mahasiswa (48,5\%); dan (b) 191 mahasiswi (51,5\%). Terkait simtom kecemasan, berikut adalah gambaran data. Pada mahasiswa laki-laki maupun perempuan, sebanyak 117 mahasiswa $(31,5 \% \%)$ tidak menunjukkan simtom kecemasan dan 254 sisanya $(68,5 \%)$ mengalami simtom kecemasan. Apabila dibandingkan, 124 mahasiswa (48,8\%) dan 130 mahasiswi (51,2\%) menunjukkan simtom kecemasan. Pada kelompok mahasiswa yang mengalami simtom kecemasan, 19 orang mengalami simtom dalam taraf ringan $(15,3 \%)$, 56 orang $(45,2 \%)$ mengalami simtom dalam taraf sedang, 34 orang $(27,4 \%)$ mengalami simtom dalam taraf berat, dan 15 orang $(12,1 \%)$ mengalami simtom dalam taraf sangat berat. Pada kelompok mahasiswi dengan simtom kecemasan, 23 orang $(17,6 \%)$ mengalami simtom dalam taraf ringan, 61 orang $(46,3 \%)$ mengalami simtom dalam taraf sedang, 26 orang $(20,6 \%)$ mengalami simtom dalam taraf berat, dan 20 orang $(15,4 \%)$ mengalami simtom dalam taraf sangat berat.

Berikut merupakan paparan data dari mahasiswa/i dengan simtom depresi. Dari seluruh mahasiswa yang berpartisipasi, sebanyak 272 mahasiswa/i (73,3\%) tidak menunjukkan simtom depresi dan 99 orang $(26,7 \%)$ mengalami simtom depresi. Dari hasil perbandingan, 53 mahasiswa $(53,5 \%)$ mengalami simtom depresi sedangkan 46 mahasiswi (46,5\%) mengalami simtom depresi. Pada kelompok mahasiswa depresif, sebanyak 30 orang $(56,6 \%)$ mengalami simtom dalam taraf ringan, $13(24,5 \%)$ orang mengalami simtom dalam taraf sedang, $7(13,2 \%)$ orang mengalami simtom dalam taraf berat, dan 3 orang $(5,7 \%)$ mengalami simtom dalam taraf sangat berat. Pada kelompok mahasiswi depresif, 23 orang (50\%) mengalami simtom dalam taraf ringan, 15 orang $(32,6 \%)$ mengalami simtom dalam taraf sedang, 4 orang $(8,7 \%)$ mengalami simtom dalam taraf berat, dan 4 orang $(8,7 \%)$ mengalami simtom dalam taraf sangat berat.

Tabel 1. Gambaran demografi mahasiswa berdasarkan jenis kelamin

\begin{tabular}{lc}
\hline Mahasiswa & Jumlah \\
\hline Laki-laki & 180 \\
\hline Perempuan & 191 \\
\hline Total & 371 \\
\hline
\end{tabular}


Tabel 2. Gambaran mahasiswa dengan simtom kecemasan

\begin{tabular}{cccccc}
\hline Jenis Kelamin & Normal & Mild & Moderate & Severe & $\begin{array}{c}\text { Extremely } \\
\text { Severe }\end{array}$ \\
\cline { 2 - 6 } & 56 & 19 & 56 & 34 & 15 \\
\hline Laki-laki & 61 & 23 & 61 & 26 & 20 \\
\hline Perempuan & 117 & 42 & 117 & 60 & 35 \\
\hline Total & \multicolumn{5}{c}{254} \\
\hline Total Simtom Kecemasan & & & \\
\hline
\end{tabular}

Tabel 3. Gambaran mahasiswa dengan simtom depresi

\begin{tabular}{cccccc}
\hline $\begin{array}{c}\text { Jenis } \\
\text { Kelamin }\end{array}$ & Normal & Mild & Moderate & Severe & $\begin{array}{c}\text { Extremely } \\
\text { Severe }\end{array}$ \\
\cline { 2 - 6 } & 127 & 30 & 13 & 7 & 3 \\
\hline Laki-laki & 145 & 23 & 15 & 4 & 4 \\
\hline Perempuan & 273 & 53 & 28 & 11 & 7 \\
\hline Total & & & 99 & & \\
\hline Total Simtom Depresif & & &
\end{tabular}

Berdasarkan pemaparan data, hasil penelitian ini sesuai dengan beberapa temuan peneliti terdahulu. Berdasarkan temuan, dapat disimpulkan bahwa lebih banyak mahasiswa/i yang mengalami simtom kecemasan dibandingkan simtom depresi. Temuan tersebut serupa dengan penelitian terdahulu (Iqbal, Gupta, \& Venkatarao, 2015). Hal ini dapat saja terjadi karena berbagai tantangan dalam dunia perkuliahan, seperti memenuhi syarat penilaian, ujian, jumlah materi yang perlu dipelajari, dan manajemen waktu (Crocker \& Luhtanen, 2003; Kumaraswamy, 2013; Misra \& McKean, 2000). Tidak terdapat perbedaan signifikan antara mahasiswa/i yang mengalami simtom kecemasan maupun depresi. Pada kelompok mahasiswa/i dengan simtom kecemasan, hasil memperlihatkan lebih banyak mahasiswa yang mengalami kecemasan dalam taraf sedang. Temuan ini sejalan dengan penelitian Beiter et. al. (2015) yang menemukan lebih banyak mahasiswa yang mengalami kecemasan dalam taraf sedang dibandingkan taraf lain (ringan, berat, sangat berat). Pada kelompok mahasiswa/i dengan simtom depresi, hasil menunjukkan lebih banyak yang mengalami depresi pada taraf ringan. Hasil temuan ini dapat diterima karena mahasiswa dengan depresi ringan dikatakan sudah mengalami permasalahan yang serius (Vredenburg, O’Brien, \& Krames, 1988). Oleh karena itu, mahasiswa dengan simtom depresi yang berat mungkin tidak dapat mengikuti perkuliahan secara adaptif.

\section{KESIMPULAN DAN SARAN}

Dari studi yang dilakukan, jumlah mahasiwa yang mengalami kecemasan atau depresi lebih banyak dibandingkan mahasiswa yang tidak mengalami simtom apapun. Tidak terdapat perbedaan signifikan antar gender dalam hal prevalensi kecemasan maupun depresi. Dalam kategori kecemasan maupun depresi, seluruh taraf dapat ditemukan pada mahasiswa (baik dari taraf ringan hingga sangat berat). Adapun tingkat kecemasan yang paling prevalen adalah taraf sedang; sedangkan tingkat depresi yan paling prevalen dari mahasiswa adalah taraf ringan.

Untuk penelitian selanjutnya, beberapa saran perlu untuk dipertimbangkan. Penelitian selanjutnya boleh menambah atau menyamaratakan jumlah mahasiswa/i dengan quota sampling. Dengan menerapkan quota sampling, maka peneliti dapat memeroleh perhitungan yang lebih akurat lagi. Penelitian berikutnya dapat menambahkan data kualitatif dari hasil wawancara untuk mengetahui sumber simtom kecemasan maupun depresi pada mahasiswa. Temuan kualitatif diharapkan dapat memberikan gambaran permasalahan untuk ditangani. Kemudian, melihat banyaknya mahasiswa/i yang mengalami simtom kecemasan maupun depresi, maka universitas perlu untuk menginformasikan mengenai layanan psikologis yang tersedia. Pemberitahuan 
tersebut diharapkan dapat mendorong mahasiswa untuk mencari bantuan dan mendiskusikan permasalahan pada psikolog maupun konselor.

\section{Ucapan Terima Kasih}

Peneliti mengucapkan terima kasih kepada seluruh mahasiswa yang telah berpartisipasi dalam penelitian ini serta pihak-pihak yang terkait yang membantu proses penelitian.

\section{REFERENSI}

Barrera, T. L., \& Norton, P. J. (2009). Quality of life impairment in generalized anxiety disorder, social phobia, and panic disorder. Journal of Anxiety Disorders, 23(8), 1086-1090. doi:10.1016/j.janxdis.2009.07.011

Beiter, R., Nash, R., McCrady, M., Rhoades, D., Linscomb, M., Clarahan, M., \& Sammut, S. (2015). The prevalence and correlates of depression, anxiety, and stress in a sample of college students. Journal of Affective Disorders, 173, 90-96. doi:10.1016/j.jad.2014.10.054

Crocker, J., \& Luhtanen, R.K. (2003). Level of self-esteem and contingencies of selfworth: unique effects on academic, social, and financial problems in college students. Personal. Soc. Psychol. Bull, 29, 701-712.

Damanik, D.E. (2006). Pengujian reliabilitas, validitas, analisis item, dan pembuatan norma Depression, Anxiety and Stress Scale (DASS). Diunduh dari http://eprints.lib.ui.ac.id/1525 3/1/94859\%2DPengujian\%20 reabilitas\%2DFull\%20Text\% 20(T\%2017892).pdf.

Doom, J. R., \& Haeffel, G. J. (2013). Teasing Apart the Effects of Cognition, Stress, and Depression on Health. American Journal of Health Behavior, 37(5), 610619.doi:10.5993/ajhb.37.5.4

Eisenberg, D., Gollust, S.E., Golberstein, E., \& Hefner, J.L. (2007). Prevalence and correlates of depression, anxiety, and suicidality among university students. Am. J. Orthopsychiatry, 77, 534-542.

Iqbal, S., Gupta, S., \& Venkatarao., E (2015). Stress, anxiety and depression among medical undergraduate students and their socio-demographic correlates. Indian J Med Res, 141 (3) 354-357. doi: 10.4103/0971-5916.156571

Kai-Wen, C. (2009). A study of stress sources among college students in Taiwan. Journal of Academic and Business Ethics. https://www.researchgate.net/profile/Rajesh_Sagar4/publication/272512778_Stress_and_ Coping_among_Adolescents_in_Selected_Schools_in_the_Capital_City_of_India/links/5 774b57808aeb9427e242795.pdf

Kostanski, M., \& Gullone, E. (1998). Adolescent body image dissatisfaction: relationships with self-esteem, anxiety, and depression controlling for body mass. J. Child Psychol. Psychiatry, 39, 255-262.

Kumaraswamy, N. (2013). Academic stress, anxiety and depression among college students- a brief review. Int. Rev. Soc. Sci. Humanit, 5, 135-143.

Lifespan News. (2006). Negative body image related to depression, anxiety and suicidality. Retrieved from http://www.lifespan.org/negative-body-image-relatedto-depressionanxiety-and-suicidality.html $\rangle$ ).

Lovibond, S. H., \& Lovibond, P. F. (1995). Manual for the Depression Anxiety Stress Scale (2nd ed.). Sydney: Psychology Foundation.

Mihăilescu, A. I., Diaconescu, L. V., Ciobanu, A. M., Donisan, T., \& Mihailescu, C. (2016). The impact of anxiety and depression on academic performance in undergraduate medical students. European Psychiatry, 33. doi:10.1016/j.eurpsy.2016.01.761 
Misra, R., \& McKean, M. (2000). College students' academic stress and its relation to their anxiety, time management, and leisure satisfaction. Am. J. Health Stud. 16, 41-51.

Mutch, C. (2005). The transiton from high school to university: An analysis of advice for students, faculty and administration. Retrieved from http://www.cshe.nagoya-u.ac.jp/ publications/ journal/no5/10.pdf

Orzech, K.M., Salafsky, D.B., \& Hamilton, L.A. (2011). The state of sleep among college students at a large public university. J. Am. Coll. Health, 59, 612-619.

Schneider, Z., Whitehead, D., LoBiondo-Wood, G., \& Haber, J. (2013). Nursing and midwifery research: Methods and critical appraisal for evidence-based practice. Chatswood, NSW: Elsevier.

Tania, M., Soetikno, N., \& Suparman, M. Y. (2019). Gambaran kecemasan dan depresi wanita dengan kanker payudara. Jurnal Muara Ilmu Sosial, Humaniora, dan Seni, 3(1), 230-237.

Tarzian, A. J., \& Cohen, M. C. (2012). Descriptive research. In J. J. Fitzpatrick, \& M. W. Kazer (Eds.), Encyclopedia of Nursing Research (pp. 122-124). New York, NY: Springer.

Trisnaramawati, F., Satiadarma, M. P., \& Soetikno, N. (2019). Gambaran kecemasan dan depresi pada orang denan systemic lupus erythematosus (SLE) di rumah sakit X. Jurnal Muara Ilmu Sosial, Humaniora, dan Seni, 3(2), 457-464.

Vredenburg, K., O'Brien, E., \& Krames, L. (1988). Depression in college students: Personality and experiential factors. Journal of Counseling Psychology, 35(4), 419425. doi:10.1037/0022-0167.35.4.419 